\title{
Kinase inhibitor screening identifies CDK4 as a potential therapeutic target for melanoma
}

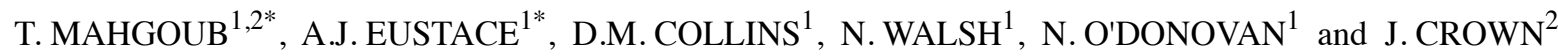 \\ ${ }^{1}$ National Institute for Cellular Biotechnology, Dublin City University, Dublin; \\ ${ }^{2}$ Department of Medical Oncology, St. Vincent's University Hospital, Dublin, Ireland
}

Received May 27, 2015; Accepted July 6, 2015

DOI: $10.3892 /$ ijo.2015.3097

\begin{abstract}
Despite recent advances in targeted therapies and immunotherapies metastatic melanoma remains only rarely curable. The objective of the present study was to identify novel therapeutic targets for metastatic melanoma. A library of 160 well-characterised and potent protein kinase inhibitors was screened in the BRAF mutant cell line Sk-Mel-28, and the NRAS mutant Sk-Mel-2, using proliferation assays. Of the 160 inhibitors tested, 20 achieved $>50 \%$ growth inhibition in both cell lines. Six of the 20 were cyclin dependent kinase (CDK) inhibitors, including two CDK4 inhibitors. Fascaplysin, a synthetic CDK4 inhibitor, was further tested in 8 melanoma cell lines. The concentration of fascaplysin required to inhibit growth by $50 \%$ ( $\mathrm{IC}_{50}$ value) ranged from 0.03 to $0.22 \mu \mathrm{M}$. Fascaplysin also inhibited clonogenic growth and induced apoptosis. Sensitivity to PD0332991, a therapeutic CDK4/6 inhibitor was also evaluated in the melanoma cell lines. PD0332991 $\mathrm{IC}_{50}$ values ranged from 0.13 to $2.29 \mu \mathrm{M}$. Similar to fascaplysin, PD0332991 inhibited clonogenic growth of melanoma cells and induced apoptosis. Higher levels of CDK4 protein correlated with lower sensitivity to PD0332991 in the cell lines. Combined treatment with PD0332991 and the BRAF inhibitor PLX4032, showed additive anti-proliferative effects in the BRAF mutant cell line Malme-3M. In summary, targeting CDK4 inhibits growth and induces apoptosis in melanoma cells in vitro, suggesting that CDK4 may be a rational therapeutic target for metastatic melanoma.
\end{abstract}

\section{Introduction}

Metastatic melanoma is generally an incurable neoplasm. Few patients achieve meaningful clinical responses to conventional cytotoxic chemotherapy. In recent years, there have been

Correspondence to: Dr Norma O'Donovan, National Institute for Cellular Biotechnology, Dublin City University, Glasnevin, Dublin 9, Ireland

E-mail: norma.odonovan@dcu.ie

*Contributed equally

Key words: melanoma, kinase inhibitor library, cyclin dependent kinase, fascaplysin, PD0332991, CDK4 significant developments in immunotherapy and molecular targeted therapy for the treatment of metastatic melanoma. Antibodies targeting immune inhibitory checkpoints, specifically CTLA4 and PD1/PD-L1 have produced meaningful improvements in melanoma survival rates (1). Inhibitors targeting BRAF produce frequent, but temporary responses in patients with V600E mutations (2). Alternative strategies to target the BRAF signalling are also been tested including MEK inhibitors, and both BRAF and MEK inhibitors are now approved as single agent therapies for metastatic melanoma. Furthermore, combining the BRAF and MEK inhibitors may further improve response rates (3).

These new therapies have resulted in improvements the 5-year survival rates for patients with metastatic melanoma but there is a need for new targets and therapies to further improve survival rates. The aim of the present study was to identify novel therapeutic targets by screening a library of 160 protein kinase inhibitors, including cyclin dependent kinase (CDK) inhibitors.

Protein kinases play central roles in the regulation of cell proliferation, differentiation and apoptosis. Deregulated kinases are often found to be oncogenic and can be central to the survival of cancer cells $(4,5)$. Progression through the cell cycle is dependent on CDKs, a family of serine/threonine kinases that consist of a catalytic subunit known as CDK and a regulatory subunit known as a cyclin. Many of the genes involved in cell cycle progression are frequently mutated in human cancers and deregulated CDK activity can be considered a hallmark of malignancy (6-9).

The tumour suppressor p16INK4a, encoded by the CDKN2A gene, is inactivated by mutation, deletion or promoter methylation in 30-70\% of melanomas (10). A 2010 study by Jonsson et al (11) demonstrated p16INK4a mutation, promoter methylation or lack of expression occurred in 16, 25 and $82 \%$ of melanoma metastases, respectively. The p16INK4a protein binds to CDK4/6 and inhibits interaction with D-type cyclins, which would otherwise stimulate passage through the G1 phase of the cell cycle. The frequent loss of p16INK4a in melanomas suggests that CDK4 activity may be unchecked in melanoma and may play a role in promoting uncontrolled proliferation of melanoma cells. Furthermore, mutation or overexpression of CDK4, combined with amplification of cyclin D1, has been implicated in resistance to BRAF inhibition in V600E-mutated melanoma cells, and amplification of cyclin D1 is detected in $17 \%$ of BRAF V600E-mutated human metastatic melanomas (12). 
The druggable nature of kinases has sparked considerable interest in pursuing CDKs as novel targets in anticancer drug development. Selective inhibition of CDKs may limit the progression of a tumour cell through the cell cycle and facilitate the induction of apoptosis $(6,13)$.

\section{Materials and methods}

Cells and reagents. Malme-3M, Sk-Mel-2, Sk-Mel-5, Sk-Mel-28, M14 and Lox-IMVI melanoma cell lines were obtained from the Department of Developmental Therapeutics, National Cancer Institute (Bethesda, MD, USA). WM-115 and WM-266-4 melanoma cell lines were obtained from the European Association Culture Collection (UK). Malme-3M, Sk-Mel-2, Sk-Mel-5, Sk-Mel-28, M14 and Lox-IMVI cell lines were maintained at $37^{\circ} \mathrm{C}$ with $5 \% \mathrm{CO}_{2}$ in RPMI-1640 medium (Sigma-Aldrich, Co. Wicklow, Ireland) with $10 \%$ fetal calf serum (FCS; Lonza, Tewkesbury, UK). WM-115 and WM-266-4 were maintained at $37^{\circ} \mathrm{C}$ with $5 \% \mathrm{CO}_{2}$ in minimal essential medium (MEM; Sigma-Aldrich) with $10 \%$ FCS (BioWhittaker, Walkersville, MD, USA), 2 mM L-glutamine (Life Technologies, Dublin, Ireland), $1 \mathrm{mM}$ nonessential amino acids (Life Technologies) and $1 \mathrm{mM}$ sodium pyruvate (Life Technologies). Stock solutions of fascaplysin (Merck Millipore, Watford, UK) (10 mM), PLX4032 (Sequoia Research Products Ltd., Pangbourne, UK) (10 mM), elacridar (Sigma-Aldrich) (10 mM) and temozolomide (Sigma-Aldrich) (103 mM) were prepared in dimethyl sulfoxide (DMSO) PD0332991 (provided by Pfizer, Peapack, NJ, USA) (10 mM) was prepared in ultrapure water.

InhibitorSelect ${ }^{T M}$ 384-well protein kinase inhibitor library I. The InhibitorSelect protein kinase inhibitor library I (Merck Millipore) was supplied with 160 protein kinase inhibitors in a 384-well plate at a volume of $25 \mu \mathrm{l}$ and a concentration of $10 \mathrm{mM}$ in DMSO and were stored at $-80^{\circ} \mathrm{C}$. Stock solutions $(1 \mathrm{mM})$ were prepared by dilution in DMSO, and stored at $-20^{\circ} \mathrm{C}$. Initial screening of the 160 protein kinase inhibitors was performed at $1 \mu \mathrm{M}$ concentration on the Sk-Mel-2 and Sk-Mel-28 cell lines. Cells/well $\left(1 \times 10^{3}\right)$ were seeded in 96-well plates. Plates were incubated overnight at $37^{\circ} \mathrm{C}$ followed by addition of drugs at the appropriate concentrations and incubated for a further 5 days until wells were $80-90 \%$ confluent. At completion of the assay the colorimetric acid phosphatase assay was used to determine cell viability.

Proliferation assays and acid phosphatase assay. All cells lines were seeded at $1 \times 10^{3}$ cells/well in 96-well plates except for Malme-3M and WM-115 which were seeded at $2 \times 10^{3}$ cells/well. Plates were incubated overnight at $37^{\circ} \mathrm{C}$ followed by addition of drug at the appropriate concentrations and incubated for a further 5 days until wells were 80-90\% confluent. All media were removed and the wells were washed once with phosphate-buffered saline (PBS; SigmaAldrich). Paranitrophenol phosphate substrate $(7.25 \mathrm{mM}$; Sigma-Aldrich) in $0.1 \mathrm{M}$ sodium acetate buffer with $0.1 \%$ Triton-X (Sigma-Aldrich) pH 5.5 was added to each well and incubated at $37^{\circ} \mathrm{C}$ for $2 \mathrm{~h}$. To stop the reaction $50 \mu \mathrm{l}$ of $1 \mathrm{M}$ $\mathrm{NaOH}$ was added and the absorbance was read at $405 \mathrm{nM}$ (reference, $620 \mathrm{nM}$ ).
Clonogenic assays. Malme-3M were seeded at 600 cells/well and Sk-Mel-2 were seeded at 125 cells/well in a 24-well plate. The cells were incubated overnight at $37^{\circ} \mathrm{C}$. Media were removed and the drugs were added at the appropriate concentrations. Drug containing medium was removed after 4 days and replaced with drug-free media. The medium was replenished every 4/5 days thereafter. Malme-3M cells were incubated for 17 days and Sk-Mel-2 cells were incubated for 14 days. When ready to stain, media were removed and the cells washed gently with PBS twice. The cells were then fixed in cold Methacare solution $\left(4^{\circ} \mathrm{C}, 75 \% \mathrm{v} / \mathrm{v}\right.$ methanol, $25 \% \mathrm{v} / \mathrm{v}$ acetic acid) for $30 \mathrm{~min}$. The Methacare solution was removed and the cells were washed twice with PBS before staining with $1 \%$ crystal violet (Cruinn Diagnostics, Dublin, Ireland) for $1 \mathrm{~h}$. The cells were then rinsed with water and left to dry. Stained colonies were counted by eye.

Cell cycle assays. Malme-3M cells $\left(2.5 \times 10^{4}\right.$ per well) were seeded in 24-well plates and incubated overnight at $37^{\circ} \mathrm{C}$. Fascaplysin was then added at the appropriate concentration and the plates incubated at $37^{\circ} \mathrm{C}$ for $48 \mathrm{~h}$. Media was collected and the wells washed once with PBS. Cells were trypsinised and added to the media collected for each sample. Cells were centrifuged at $300 \mathrm{x} \mathrm{g}$ for $5 \mathrm{~min}$ and the media aspirated. The cell pellet was resuspended in $150 \mu \mathrm{l}$ PBS and transferred to a round bottomed 96-well plate. The plate was centrifuged at $300 \mathrm{x}$ g for $5 \mathrm{~min}$ and the supernatant aspirated leaving $\sim 15 \mu \mathrm{l}$ in each well. The remaining volume was used to resuspend the cells and $200 \mu \mathrm{l}$ of ice cold $70 \%$ ethanol was added. The plates were then stored at $-20^{\circ} \mathrm{C}$ for $2 \mathrm{~h}$. After fixing, the cells were spun at $450 \mathrm{x} \mathrm{g}$ for $5 \mathrm{~min}$, the supernatant removed, washed with $200 \mu \mathrm{l}$ of PBS and spun again at $450 \mathrm{x}$ g. The PBS was then removed and $200 \mu \mathrm{l}$ of Guava cell cycle reagent (Merck Millipore) was added to each well. The cells were mixed by pipetting and stored at room temperature shielded from the light for $30 \mathrm{~min}$. Cells were analysed on the Guava easyCyte (Merck Millipore) and the data were analysed using ModFit LT software (Verity Software House, Topsham, ME, USA).

Terminal DNA transferase-mediated dUTP nick end labelling (TUNEL) assay. The TUNEL assays were performed using the Guava TUNEL kit for flow cytometry (Merck Millipore), according to the manufacturer's protocol. Briefly, $2.5 \times 10^{4}$ cells were seeded per well in 24-well plates and incubated overnight at $37^{\circ} \mathrm{C}$, followed by addition of drug at the appropriate concentrations. After $48 \mathrm{~h}$, media were collected and the wells washed once with PBS. Cells were trypsinised and added to the media collected for each sample. Cells were centrifuged at $300 \mathrm{x} \mathrm{g}$ for $5 \mathrm{~min}$ and the medium was aspirated. The pellet was re-suspended in $150 \mu \mathrm{l}$ of PBS and transferred to a round bottomed 96 -well plate. A total of $50 \mu$ l of $4 \%$ paraformaldehyde (Sigma-Aldrich) made up in PBS was added to the wells and mixed. Cells were incubated at $4^{\circ} \mathrm{C}$ for $60 \mathrm{~min}$. The plate was centrifuged at $300 \mathrm{x}$ g for $5 \mathrm{~min}$ and the supernatant aspirated leaving $\sim 15 \mu \mathrm{l}$ in each well. The remaining volume was used to resuspend the cells and $200 \mu 1$ of ice cold $70 \%$ ethanol (Sigma-Aldrich) was added to the cells. The plates were then stored at $-20^{\circ} \mathrm{C}$ for $2 \mathrm{~h}$. After fixation, the cells including positive and negative controls were spun at $300 \mathrm{x} g$ for $5 \mathrm{~min}$. Cells were washed a further 2 times at $300 \times \mathrm{g}$ with wash buffer. 
Table I. Percentage growth inhibition ( \pm standard deviation) by the 20 most active compounds tested at $1 \mu \mathrm{M}$ in Sk-Mel-2 and Sk-Mel-28 melanoma cell lines.

$\%$ Growth inhibition

Sk-Mel-28 Sk-Mel-2

\section{Akt inhibitor IV}

Alsterpaullone, 2-Cyanotheyl

Aurora kinase/CDK inhibitor

CDK $1 / 2$ inhibitor III

CDK 4 inhibitor III

Cdk/crk inhibitor

EGFR inhibitor

Fascaplysin, synthetic

Herbimycon A, streptomyces sp.

IC261

JNK inhibitor

K-252a, Nocardiopsis sp.

MK2a inhibitor

$86.3 \pm 6.4 \quad 95.3 \pm 1.7$

$65.6 \pm 13.0 \quad 64.5 \pm 4.1$

$55.3 \pm 21.8 \quad 62.9 \pm 5.6$

$99.9 \pm 0.0 \quad 98.0 \pm 1.0$

$72.6 \pm 22.853 .9 \pm 8.5$

$99.8 \pm 0.0 \quad 99.6 \pm 0.2$

$87.7 \pm 5.7 \quad 94.3 \pm 0.3$

$99.2 \pm 0.6 \quad 98.0 \pm 1.0$

$73.9 \pm 15.3 \quad 89.6 \pm 3.8$

$87.5 \pm 7.0 \quad 93.8 \pm 1.2$

$91.5 \pm 1.3 \quad 95.9 \pm 1.0$

$93.3 \pm 0.6 \quad 92.8 \pm 3.3$

$92.6 \pm 1.9 \quad 93.9 \pm 1.9$

PDGF receptor tyrosine kinase inhibitor IV $89.9 \pm 1.0 \quad 95.3 \pm 1.4$

PDK1/AKT/Flt dual pathway inhibitor

PKR inhibitor

PI-103

Rapamycin

Staurosporine, streptomyces $\mathrm{sp}$.

TGF- $\beta$ RI inhibitor III

$99.9 \pm 0.0 \quad 99.8 \pm 0.3$

$68.0 \pm 2.4 \quad 83.7 \pm 3.3$

$89.0 \pm 1.3 \quad 79.2 \pm 6.7$

$66.8 \pm 5.0 \quad 65.5 \pm 5.9$

$99.2 \pm 0.3 \quad 99.6 \pm 0.4$

$75.5 \pm 3.5 \quad 74.5 \pm 8.2$

The wash buffer was aspirated and $25 \mu 1$ of DNA labelling mix was added to each well and the cells mixed. The plates were covered with parafilm and incubated for $60 \mathrm{~min}$ at $37^{\circ} \mathrm{C}$. Rinsing buffer $(200 \mu \mathrm{l})$ was then added to each well and the plates spun at $300 \mathrm{x}$ g for $5 \mathrm{~min}$. The supernatant was aspirated and $50 \mu \mathrm{l}$ of anti-BrdU staining mix added to each well, with the plate stored in the dark, at room temperature for $30 \mathrm{~min}$. At the end of the incubation $150 \mu \mathrm{l}$ of rinsing buffer was added to each well. Cells were analysed on the Guava EasyCyte (Merck Millipore). Positive and negative controls supplied with the kit were performed with each assay.

Protein extraction and western blotting. RIPA buffer (500 $\mu$; Sigma-Aldrich) with $1 \mathrm{X}$ protease inhibitors, $2 \mathrm{mM}$ phenylmethanesulphonylflouride (PMSF) and $1 \mathrm{mM}$ sodium orthovanadate (Sigma-Aldrich) was added to cells and incubated on ice for $20 \mathrm{~min}$. Following centrifugation at $16,000 \mathrm{x} \mathrm{g}$ for $10 \mathrm{~min}$ at $4^{\circ} \mathrm{C}$ the resulting lysate was stored at $-80^{\circ} \mathrm{C}$. Protein quantification was performed using the bicinchoninic acid (BCA) assay (Life Technologies). Protein $(40 \mu \mathrm{g})$ in sample buffer [ $3 \mathrm{mM}$ Tris $\mathrm{HCl} ; 5 \%$ sodium dodecyl sulphate (SDS); $12.5 \% \beta$-mercaptoethanol; $29 \%$ glycerol; $0.1 \%$ bromophenol blue] was heated to $95^{\circ} \mathrm{C}$ for $5 \mathrm{~min}$ and proteins were separated on $10 \%$ pre-cast Tris-glycine gels (Lonza). The resolved proteins were then transferred to nitrocellulose membranes (Life Technologies) using the iBlot transfer system (Life Technologies). The membrane was blocked with $5 \%$ milk powder (Bio-Rad Laboratories, Hempstead, UK) in
$0.1 \%$ PBS-Tween at room temperature for $1 \mathrm{~h}$, then incubated overnight at $4^{\circ} \mathrm{C}$ in primary antibody with $0.1 \%$ PBS-Tween in 5\% milk powder. Primary antibodies used were anti-CDK4 (1:1,000; Santa Cruz Biotechnology, Heidelberg, Germany), anti-cyclin D1 (1:1,000; Cell Signaling Technology, Leiden, The Netherlands), anti-Rb (1:1,000; Cell Signaling Technology), anti-phospho-Rb (1:3,000; Cell Signaling Technology), and anti- $\alpha$-tubulin (1:1,000; Sigma-Aldrich). The membrane was washed 3 times with $0.5 \%$ PBS-Tween and then incubated at room temperature with anti-mouse (Sigma-Aldrich) or antirabbit (Sigma-Aldrich) secondary antibody in 5\% milk powder with $0.5 \%$ PBS-Tween for $1 \mathrm{~h}$. The membrane was washed three times with $0.5 \%$ PBS-Tween followed by one wash with PBS alone. Detection was performed using Luminol (Santa Cruz Biotechnology) or ECL ${ }^{\mathrm{TM}}$ Advance western blotting detection kit (GE Healthcare, Buckinghamshire, UK).

Statistical analysis. $\mathrm{IC}_{50}$ values and combination index $(\mathrm{CI})$ values were calculated using CalcuSyn software (Biosoft, Cambridge, UK). The Student's t-test was used to determine the significance of the effects of fascaplysin and PD0332991 on the levels of cell cycle arrest and apoptosis induction, where a P-value of $<0.05$ was deemed significant. The Pearson's correlation was used to examine the relationship between expression of CDK4, cyclin D1, Rb and phospho-Rb by western blotting and sensitivity to fascaplysin and PD0332991.

\section{Results}

Melanoma cells are sensitive to cyclin dependent kinase inhibitors. Of the 160 protein kinase inhibitors tested 29 achieved $\geq 50 \%$ growth inhibition in the Sk-Mel- 2 cell line when tested at $1 \mu \mathrm{M}$ concentration. Twenty compounds achieved $\geq 50 \%$ growth inhibition in the Sk-Mel-28 cell line when tested at the same dose. The 20 compounds that achieved $\geq 50 \%$ growth inhibition in the Sk-Mel-28 cell line achieved similar levels of inhibition in the Sk-Mel-2 cell line (Table I). CDK inhibitors represented 6 of the 20 compounds. Four CDK1/2 inhibitors were identified, achieving between $55.3-99.8 \%$ growth inhibition in Sk-Mel-28 cells and 62.9-99.6\% growth inhibition in Sk-Mel-2 cells. Two CDK4 inhibitors, CDK4 inhibitor III and fascaplysin, achieved 72.6 and $99.2 \%$ growth inhibition in Sk-Mel-28 cells and 53.9 and $98.0 \%$ growth inhibition in Sk-Mel-2 cells, respectively.

Fascaplysin inhibits the growth of melanoma cells. The anti-proliferative effect of synthetic fascaplysin was further investigated in a panel of 8 melanoma cell lines. All cell lines were sensitive to fascaplysin at nanomolar concentrations, with $\mathrm{IC}_{50}$ values ranging from 32.9 to $221.3 \mathrm{nM}$ (Fig. 1 and Table II). The NRAS mutated Sk-Mel-2 cells and the most sensitive BRAF mutated cell line Malme-3M were selected for further testing. Fascaplysin significantly inhibited the clonogenic growth of both Malme-3M and Sk-Mel-2 cells (Fig. 2).

Fascaplysin induces apoptosis in melanoma cell lines. To determine if the anti-proliferative effects of fascaplysin were cytostatic or cytocidal, we performed cell cycle analysis. In Malme-3M cells, 48-h treatment with fascaplysin induced a significant increase in the subG1 fraction (Fig. 3A), to 


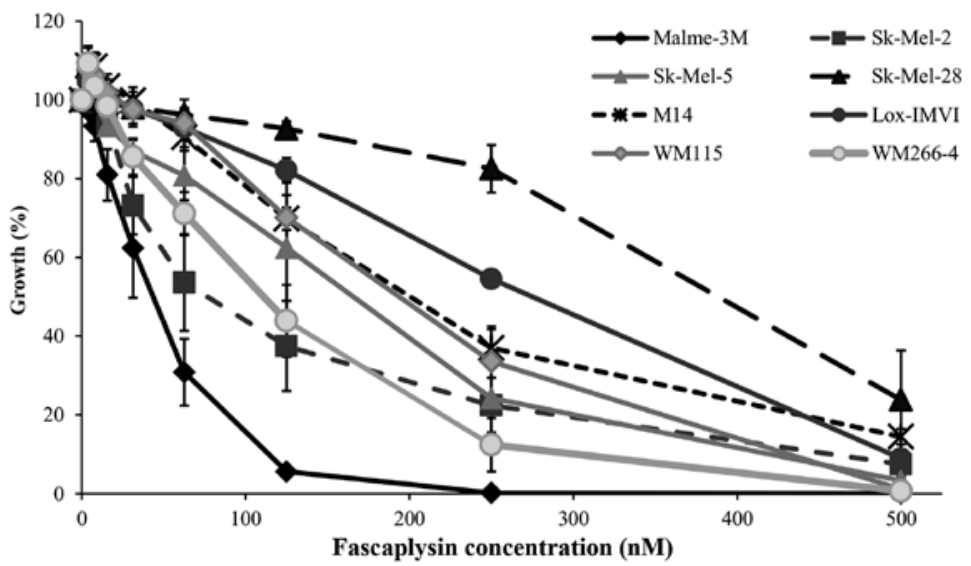

Figure 1. Fascpalysin in melanoma cells. Percentage growth inhibition by synthetic fascaplysin in a panel of 8 melanoma cell lines. Error bars represent the standard deviation of triplicate independent experiments.

A

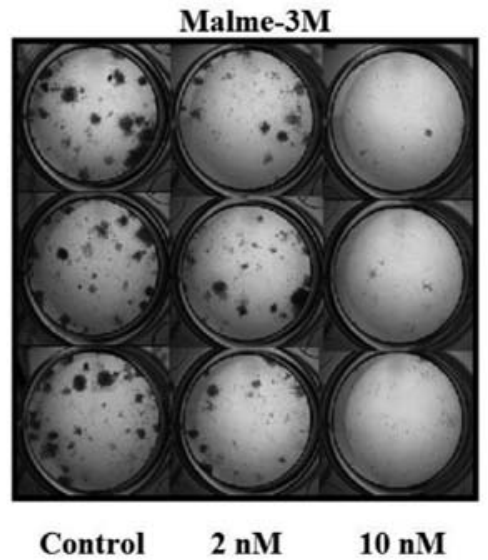

B

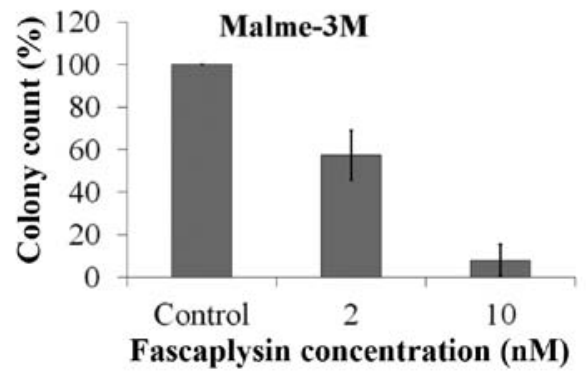

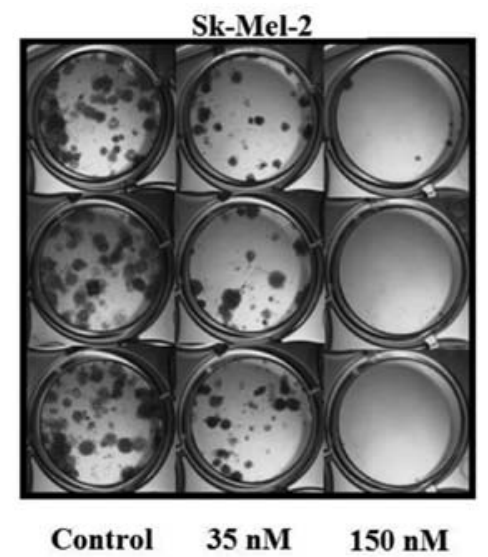

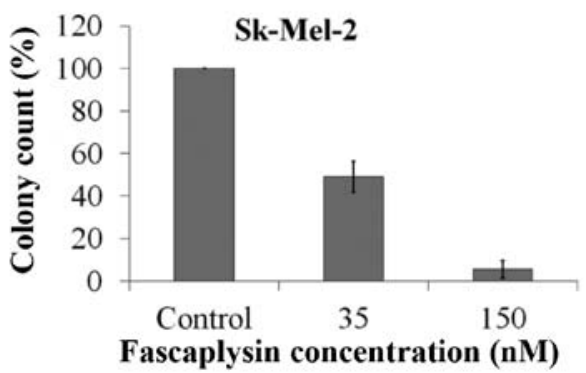

Figure 2. Effect of synthetic fascaplysin on clonogenic growth of melanoma cells. Representative images of clonogenic assays for (A) Malme-3M and (B) Sk-Mel-2 cells treated with fascaplysin are shown above the triplicate results. Error bars represent the standard deviations of triplicate independent experiments.

$19.3 \pm 2.7 \%$ in response to $90 \mathrm{nM}$ fascaplysin $(\mathrm{P}=0.020)$ compared with a subG1 fraction of $8.6 \pm 0.1 \%$ for control. To confirm the increase in the subG1 fraction was due to apoptosis induction, we used the TUNEL assay. Treatment with fascaplysin caused a small but significant increase in apoptosis in both Malme-3M cells (90 nM, 15.3 $\pm 0.9 \%$; $\mathrm{P}=0.0002)$ and Sk-Mel-2 cells (225 nM, 12.1 $\pm 1.6 \%$; $\mathrm{P}=0.006)$ (Fig. 3B).

Evaluation of PD0332991 activity in melanoma cells. As fascaplysin, a laboratory grade CDK4 inhibitor, showed significant activity in the melanoma cell lines, we tested a therapeutic CDK4/6 inhibitor PD0332991 in the panel of melanoma cell lines. Surprisingly, although PD0332991 is a more potent inhibitor of $\mathrm{CDK} 4\left(\mathrm{IC}_{50}=0.011 \mu \mathrm{M}\right.$ compared to $0.35 \mu \mathrm{M}$ for fascaplysin), the melanoma cell lines were generally less sensitive to PD0332991 than to fascaplysin with $\mathrm{IC}_{50}$ values ranging from 0.13 to $2.29 \mu \mathrm{M}$ (Table II and Fig. 4). The Sk-Mel-2, Sk-Mel-28, M14 and WM-115 cell lines showed relative resistance to $\mathrm{PD} 0332991$ with $\mathrm{IC}_{50}$ values $>1 \mu \mathrm{M}$. Notably, the WM-266-4 cell line, derived from a metastatic tumour, was sensitive, while the WM-115 cell line, derived from the primary tumour from the same patient, was resistant to PD0332991.

PD0332991 also inhibited clonogenic growth and induced apoptosis in Malme-3M and Sk-Mel-2 cells, albeit at higher concentrations than fascaplysin (Fig. 5A and B). In the 


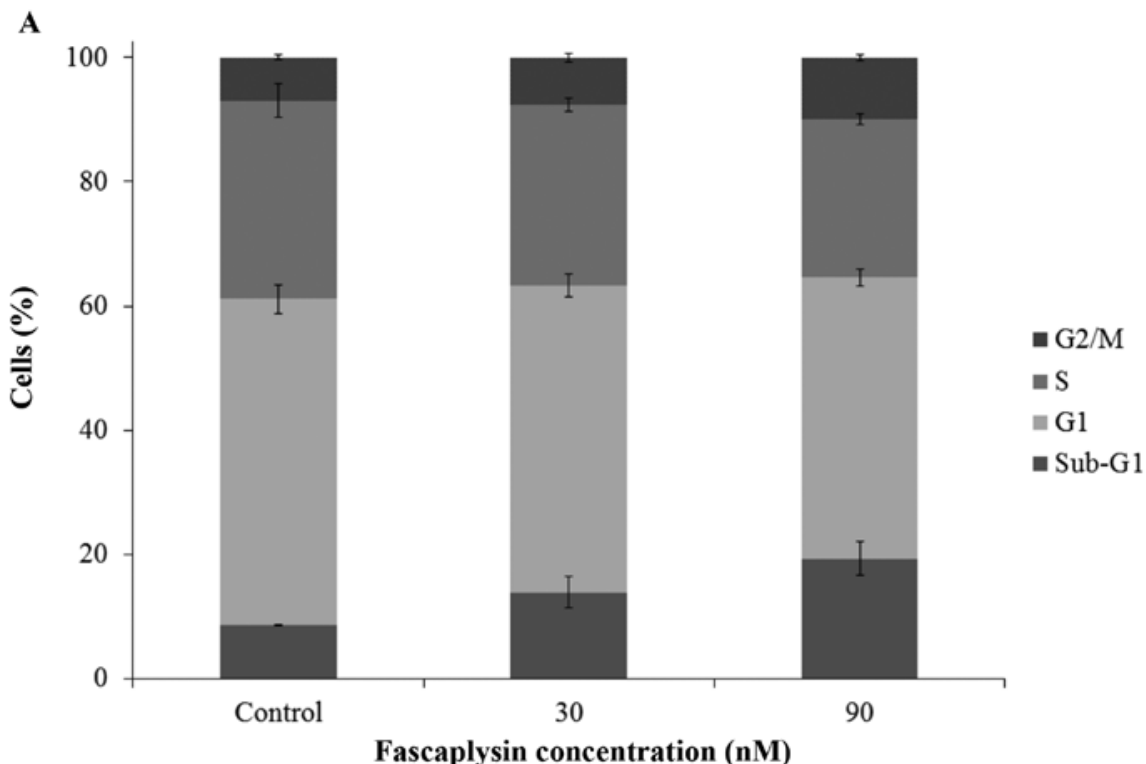

B

Fascaplysin concentration $(\mathrm{nM})$
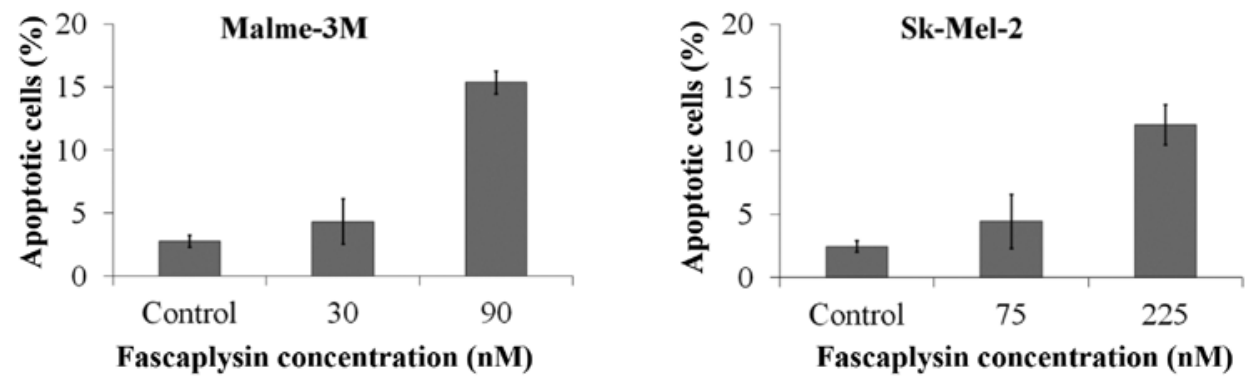

Figure 3. Fascaplysin induces apoptosis. (A) Cell cycle assay results for Malme-3M cells treated with fascaplysin, showing the percentage of cells in the subG1, G1, S and G2/M phases of the cell cycle. Cells were untreated (control) or treated with variable concentrations of fascaplysin. (B) The percentage apoptosis induction caused by fascaplysin treatment, measured by TUNEL assay, in Malme-3M and Sk-Mel-2 cells. Error bars represent the standard deviations of triplicate independent experiments.

Table II. $\mathrm{IC}_{50}$ concentrations of fascaplysin (nM) and PD0332991 $(\mu \mathrm{M})$ in a panel of melanoma cell lines.

\begin{tabular}{lccc}
\hline & $\begin{array}{c}\text { Mutation } \\
\text { status }\end{array}$ & $\begin{array}{c}\text { Fascaplysin } \\
(\mathrm{nM})\end{array}$ & $\begin{array}{c}\text { PD0332991 } \\
(\mu \mathrm{M})\end{array}$ \\
\hline Sk-Mel-2 & NRAS & $74.5 \pm 6.1$ & $2.14 \pm 0.24$ \\
Malme-3M & BRAF & $32.9 \pm 1.7$ & $0.14 \pm 0.01$ \\
Sk-Mel-5 & BRAF & $93.0 \pm 11.1$ & $0.50 \pm 0.05$ \\
Sk-Mel-28 & BRAF & $220.0 \pm 19.1$ & $1.83 \pm 0.18$ \\
M14 & BRAF & $178.7 \pm 23.4$ & $2.29 \pm 0.28$ \\
Lox-IMVI & BRAF & $221.3 \pm 18.4$ & $0.30 \pm 0.03$ \\
WM115 & BRAF & $166.6 \pm 25.9$ & $1.00 \pm 0.11$ \\
WM266-4 & BRAF & $87.5 \pm 13.5$ & $0.13 \pm 0.01$ \\
\hline
\end{tabular}

Standard deviations represent the deviation of triplicate independent experiments.

sensitive Malme-3M cells, 48-h treatment with PD0332991 $(390 \mathrm{nM})$ induced apoptosis in $14.9 \pm 2.3 \%$ of cells $(\mathrm{P}=0.004)$. PD0332991 induced apoptosis in $44.9 \pm 17.2 \%$ of Sk-Mel-2 cells following 48-h treatment at a dose of $6 \mu \mathrm{M}(\mathrm{P}=0.05)$ (Fig. 5C).

Drug combination assays were performed to examine the effect of PD0332991 combined with temozolomide and the BRAF inhibitor PLX4032. Concurrent treatment with PD0332991 and temozolomide did not improve response compared to PD0332991 alone (data not shown). However, the combination of PD0332991 and PLX4032 was found to be additive, with a combination index $\left(\right.$ at $\mathrm{ED}_{50}$ ) of $1.02 \pm 0.09$, in the Malme-3M cell line (Fig. 6).

CDK4 expression correlates with response to PD0332991. To determine if the differential response to PD0332991 in the melanoma cell lines is due to drug efflux we tested the effect of an inhibitor of the drug efflux pumps P-glycoprotein and breast cancer resistance protein (BCRP), in two cell lines which displayed resistance to PD0332991, SK-Mel-2 and WM115. Elacridar (GF120918, 0.5 $\mu \mathrm{M}$ ) did not enhance response to PD0332991 in either of the cell lines (data not shown).

$\mathrm{CDK} 4$, cyclin $\mathrm{D} 1, \mathrm{Rb}$ and phospho-Rb protein levels were evaluated by western blotting. CDK4 protein was detected at high levels in the panel of 8 melanoma cell lines (Fig. 7A). No correlation was observed between expression of CDK4 and sensitivity to fascaplysin $(r=0.036, P=0.933)$. In contrast, high levels of CDK4 expression were significantly associated with reduced sensitivity to PD0332991, that is higher $\mathrm{IC}_{50}$ values ( $\mathrm{r}=0.713, \mathrm{P}=0.047$ ) (Fig. 7B). No significant correlation was observed between sensitivity to either fascaplysin or PD0332991 and cyclin D1, Rb and phospho-Rb levels. 


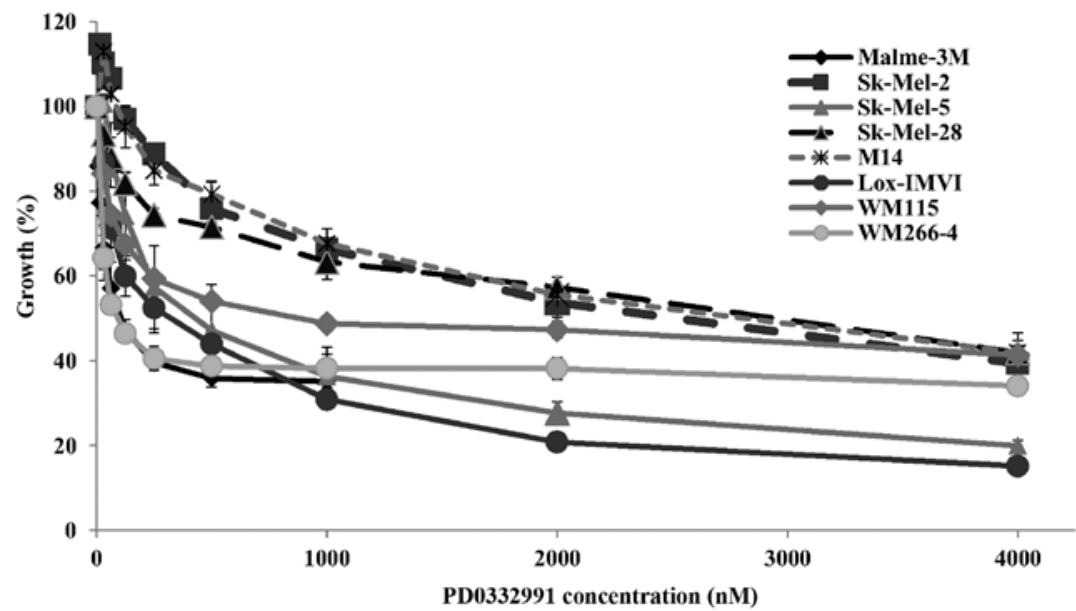

Figure 4. Sensitivity to the therapeutic CDK4/6 inhibitor PD0332991. Percentage growth inhibition by PD0332991 in a panel of 8 melanoma cell lines. Error bars represent the deviation of triplicate independent experiments.

A.

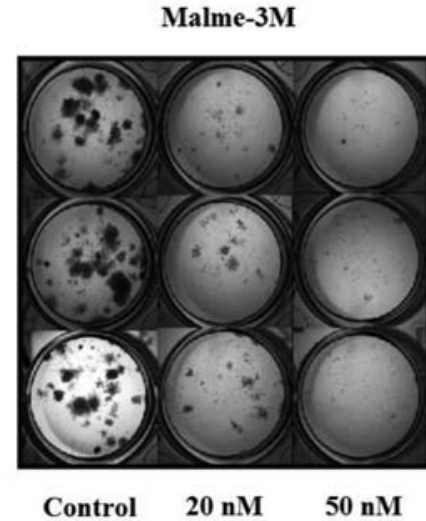

B.
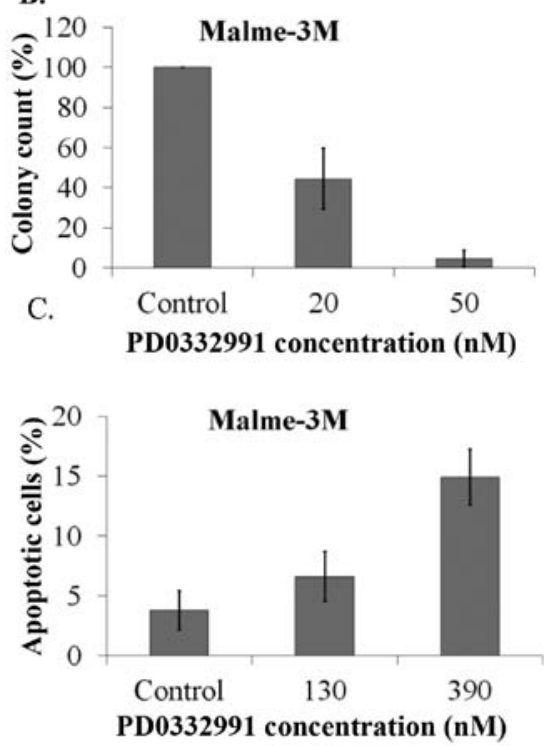

Sk-Mel-2

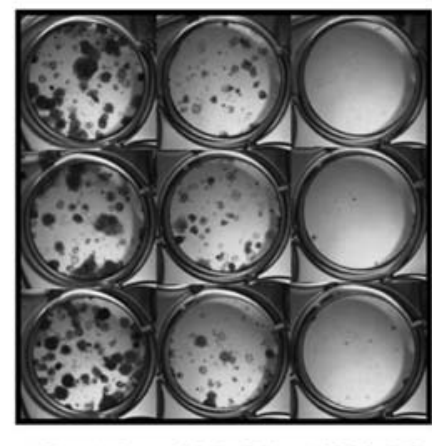

Control $200 \mathrm{nM} \quad 1000 \mathrm{nM}$
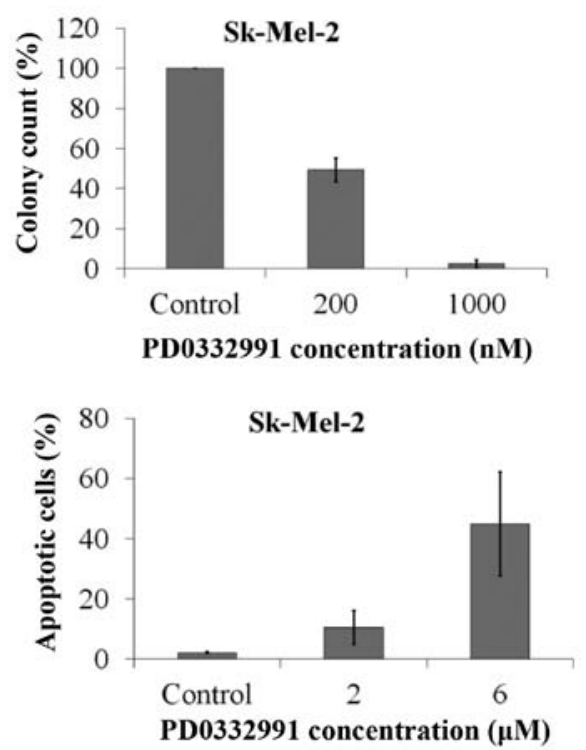

Figure 5. PD0332991 inhibits clonogenic growth and induces apoptosis. Effect of PD0332991 on the clonogenic growth of (A) Malme-3M and (B) Sk-Mel-2 cells. (C) Percentage apoptosis induction by PD0332991, measured by TUNEL assay, in Malme-3M and Sk-Mel-2 cells. Error bars represent the standard deviations of triplicate independent experiments.

\section{Discussion}

To identify novel targets for treatment, we screened a library of 160 protein kinase inhibitors in 2 melanoma cell lines. For a disease representative approach, we selected 2 melanoma cell lines with genetic mutations common to melanoma. The Sk-Mel-2 cell line carries an NRAS mutation, NRAS is mutated in $18 \%$ of melanomas (range, $0-50 \%$ ) (14). The Sk-Mel-28 cell 


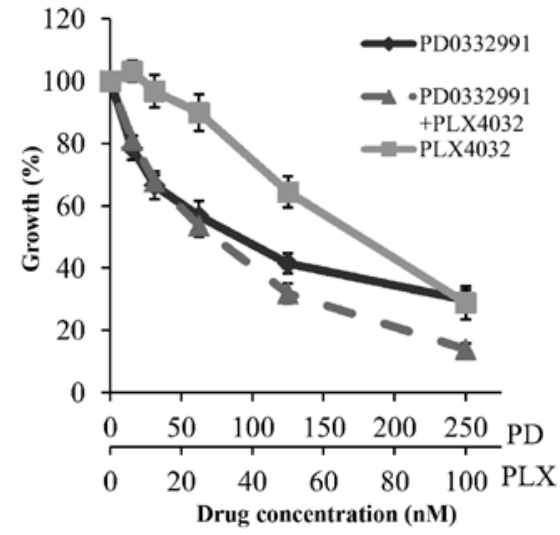

Figure 6. Dual targeting of CDK4 and BRAF. Effect of combining PD0332991 with PLX4032 on proliferation of Malme-3M cells, using a fixed combination ratio of 2.5:1 PD0332991 to PLX4032. Error bars represent the standard deviations of triplicate independent experiments.
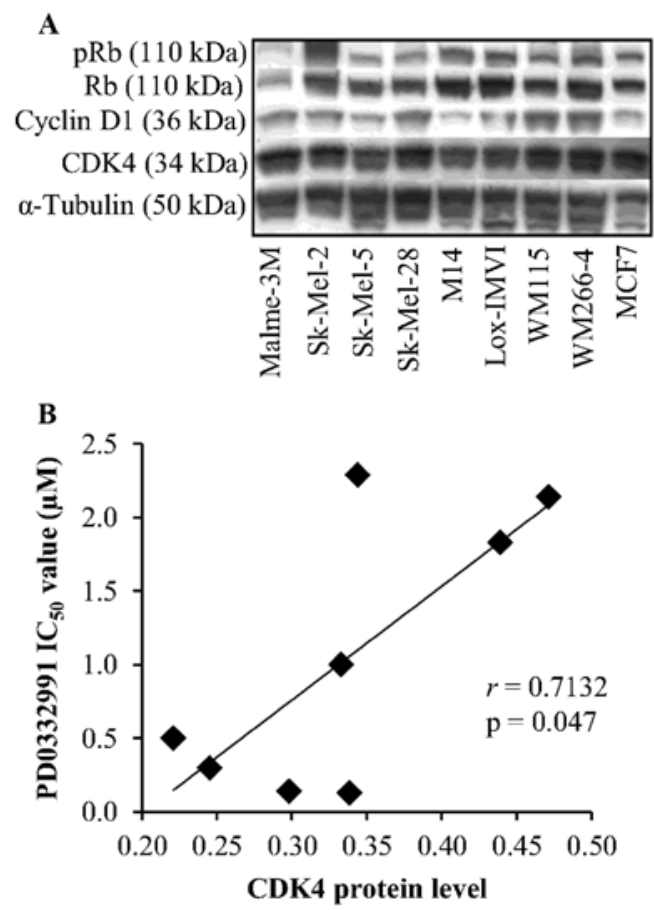

Figure 7. Potential PD0332991 predictive biomarkers. (A) pRb, Rb, cyclin D1 and CDK4 protein expression relative to $\alpha$-tubulin determined by western blotting in a panel of 8 untreated melanoma cell lines. The MCF7 breast cancer cell line was used as a positive control. (B) Correlation between CDK4 protein levels, determined by densitometry of triplicate western blots, and sensitivity to PD0332991 in the panel of 8 melanoma cell lines.

line is BRAF mutated, BRAF is mutated in $41 \%$ of melanomas (range 22-72\%) (14). NRAS and BRAF mutations are believed to be mutually exclusive in melanoma (15).

Six of the 20 most effective compounds were CDK inhibitors. This result is not surprising considering the role of CDKs in cell cycle control. Progression through the mammalian cell cycle is a tightly regulated process. Along with their associated cyclins, CDKs are master regulators of cell proliferation. More than $11 \mathrm{CDKs}$ have been identified, with CDKs 1-4 and 6 directly involved in driving the cell cycle. Deregulated CDK activity results in uncontrolled proliferation and represents a hallmark of malignancy (16).
Activating mutations, or amplification of CDK4 have been described in both familial and sporadic cases of melanoma (17). Intact p16INK4a inhibits CDK4 activity and loss of p16, which occurs frequently in melanoma, results in abnormal CDK4 activity (18). Amplification of cyclin D, which binds to CDK4, can drive cell cycle progression, and has been observed in a subset of melanomas (19). These factors provide evidence that CDK4 plays an important role in melanoma progression. Thus, we chose to further evaluate CDK4 inhibition using fascaplysin, a synthetic selective CDK4 inhibitor.

Fascaplysin was originally isolated as a compound showing antimicrobial activity from the sponge Fascaplysinopsis sp (20). It is a selective inhibitor of CDK4 $\left(\mathrm{IC}_{50}=0.35 \mu \mathrm{M}\right)$ and CDK6 $\left(\mathrm{IC}_{50}=3.4 \mu \mathrm{M}\right)$ and not selective for the other CDKs or other kinases $(21,22)$. Fascaplysin, or derivatives of fascaplysin, have shown direct antitumour activity, by inducing apoptosis, and anti-angiogenic effects in preclinical tumour models, including sarcoma (23) and a number of the National Cancer Institute panel of cell lines (24).

All melanoma cell lines tested were sensitive to fascaplysin at concentrations in the nanomolar range. Notably, WM-266-4 cells were significantly more sensitive to growth inhibition by fascaplysin than WM-115 cells. WM-115 is a primary melanoma cell line, while WM-266-4 is a metastatic cell line, derived from the same patient (25). The different sensitivity may be related to the faster proliferation rate of the metastatic cell line WM-266-4 (26). The other cell lines used in this study are all derived from metastatic tumours, and all show similar sensitivity to fascaplysin as the WM-266-4 cell line, with the exception of Lox-IMVI which shows intermediate sensitivity. The lower sensitivity in the primary WM-115 cells, suggests that primary melanomas might be less sensitive to CDK4 inhibition than metastatic tumours but this would require further testing in a larger panel of cell lines derived from primary and metastatic tumours.

Consistent with previous studies showing that fascaplysin can induce apoptosis in vitro and in vivo $(23,27)$ we showed that fascaplysin increases the subG1 fraction and apoptosis induction in melanoma cells.

Although fascaplysin has not been tested in cancer patients, several multi-target CDK inhibitors are currently being evaluated in clinical trials (5). PD0332991 is a highly specific inhibitor of CDK4 $\left(\mathrm{IC}_{50}=0.011 \mu \mathrm{M}\right)$ and CDK6 $\left(\mathrm{IC}_{50}=0.016 \mu \mathrm{M}\right)(28)$ and is currently in phase II trials in several solid tumours. One phase II study is testing PD0332991 in refractory solid tumours including stage IV melanoma (NCT01037790).

Four of the 8 melanoma cell lines tested were sensitive to PD0332991. Loss of retinoblastoma protein $(\mathrm{Rb})$ has been correlated with resistance to PD0332991 (29), however, all of the melanoma cell lines tested expressed detectable levels of $\mathrm{Rb}$. Analysis of the mutational status of the panel of cell lines using the COSMIC database (http://cancer.sanger. ac.uk/cancergenome/projects/cell_lines/) and the Cancer Cell Line Encyclopedia (http://www.broadinstitute.org/ccle), suggest that mutations in CDK4 or p16INK4A do not predict response or resistance, as only one of the melanoma cell lines (SK-MEL-28) has a mutation in CDK4 and there are no reported mutations in p16INK4A in these cell lines. SanchezMartinez et al (30) previously reported that PD0332991 is 
a substrate for the drug efflux pumps P-glycoprotein (P-gp) and breast cancer resistance protein (BCRP). Therefore, we tested elacridar, an inhibitor of P-gp and BCRP, but it had no impact on response to PD0332991 in the cell lines tested, suggesting that P-gp and BCRP do not play a role in resistance to PD0332991 in the melanoma cell lines. However, P-gp expression has been reported in $\sim 50 \%$ of primary melanomas and $74 \%$ of metastatic melanomas (31), and thus may impact on sensitivity to PD0332991 in melanoma patients.

Using semi-quantitative western blotting, we found that lower CDK4 protein levels correlated with sensitivity to PD0332991 in the panel of 8 cell lines. A recent study showed that 37 out of 47 melanoma cell lines were sensitive to PD0332991 in vitro $\left(\mathrm{GI}_{50}<1 \mu \mathrm{M}\right)$. Sensitivity to PD0332991 did not correlate with CDK4 mRNA expression in that study, but low levels of CDKN2A mRNA, or mutation or loss of CDKN2A correlated with sensitivity (32). Further evaluation of CDK4 protein levels in a larger panel of cell lines, and ultimately in tumour samples from melanoma patients treated with PD0332991, would be required to definitively determine the clinical relevance of CDK4 protein as a predictive biomarker for PD0332991 response.

The reason for the differential sensitivity to fascaplysin and PD0332991 is not fully understood. It may be due to the reported ability of fascaplysin to bind to and intercalate into DNA (33).

Although combinations of either fascaplysin or PD0332991 with temozolomide, a derivative of dacarbazine commonly used to treat melanoma, did not show enhanced anti-proliferative effects, combined treatment with PD0332991 and the therapeutic BRAF inhibitor PLX4032 was additive in the BRAF mutated cell line tested. A recent study by Jalili et al (34) showed that dual inhibition of CDK2 and CDK4 enhanced response to BRAF and MEK inhibitors in melanoma cells in vitro and in vivo. Thus, combining CDK4 inhibition with BRAF or MEK targeted therapies may provide greater therapeutic benefit than combinations with chemotherapy.

In summary, using kinase inhibitor screening, we showed that melanoma cells are particularly sensitive to CDK inhibition in vitro. Further testing of the therapeutic CDK4 inhibitor PD0332991 showed that 4 out of 8 melanoma cell lines tested are sensitive to CDK4 inhibition and that CDK4 inhibition induces apoptosis in melanoma cells. Our results suggest that CDK4 inhibition represents a promising approach for the treatment of metastatic melanoma.

\section{Acknowledgements}

The present research was supported by the Cancer Clinical Research Trust.

\section{References}

1. Bhatia S, Tykodi SS, Lee SM and Thompson JA: Systemic therapy of metastatic melanoma: On the road to cure. Oncology (Williston Park) 29: 126-135, 2015.

2. Dummer R and Flaherty KT: Resistance patterns with tyrosine kinase inhibitors in melanoma: New insights. Curr Opin Oncol 24: 150-154, 2012

3. Long GV, Stroyakovskiy D, Gogas H, Levchenko E, de Braud F, Larkin J, Garbe C, Jouary T, Hauschild A, Grob JJ, et al: Combined BRAF and MEK inhibition versus BRAF inhibition alone in melanoma. N Engl J Med 371: 1877-1888, 2014.
4. Hunter T and Cooper JA: Protein-tyrosine kinases. Annu Rev Biochem 54: 897-930, 1985.

5. Cicenas $\mathrm{J}$ and Valius M: The CDK inhibitors in cancer research and therapy. J Cancer Res Clin Oncol 137: 1409-1418, 2011.

6. Diaz-Padilla I, Siu LL and Duran I: Cyclin-dependent kinase inhibitors as potential targeted anticancer agents. Invest New Drugs 27: 586-594, 2009.

7. Malumbres $M$ and Barbacid M: Cell cycle, CDKs and cancer: A changing paradigm. Nat Rev Cancer 9: 153-166, 2009.

8. Malumbres $\mathbf{M}$ and Barbacid M: Cell cycle kinases in cancer. Curr Opin Genet Dev 17: 60-65, 2007.

9. Lapenna $\mathrm{S}$ and Giordano A: Cell cycle kinases as therapeutic targets for cancer. Nat Rev Drug Discov 8: 547-566, 2009.

10. Sharpless E and Chin L: The INK4a/ARF locus and melanoma. Oncogene 22: 3092-3098, 2003.

11. Jonsson A, Tuominen R, Grafström E, Hansson J and Egyhazi S: High frequency of p16(INK4A) promoter methylation in NRASmutated cutaneous melanoma. J Invest Dermatol 130: 2809-2817, 2010.

12. Smalley KS, Lioni M, Dalla Palma M, Xiao M, Desai B, Egyhazi S, Hansson J, Wu H, King AJ, Van Belle P, et al: Increased cyclin D1 expression can mediate BRAF inhibitor resistance in BRAF V600E-mutated melanomas. Mol Cancer Ther 7: 2876-2883, 2008.

13. Sausville EA: Complexities in the development of cyclindependent kinase inhibitor drugs. Trends Mol Med 8 (Suppl): S32-S37, 2002.

14. Lee JH, Choi JW and Kim YS: Frequencies of BRAF and NRAS mutations are different in histological types and sites of origin of cutaneous melanoma: A meta-analysis. Br J Dermatol 164: 776-784, 2011.

15. Meier F, Schittek B, Busch S, Garbe C, Smalley K, Satyamoorthy K, Li G and Herlyn M: The RAS/RAF/MEK/ERK and PI3K/AKT signaling pathways present molecular targets for the effective treatment of advanced melanoma. Front Biosci 10: 2986-3001, 2005.

16. Harper JW and Adams PD: Cyclin-dependent kinases. Chem Rev 101: 2511-2526, 2001.

17. Walker GJ, Flores JF, Glendening JM, Lin AH, Mark1 ID and Fountain JW: Virtually 100\% of melanoma cell lines harbor alterations at the DNA level within CDKN2A, CDKN2B, or one of their downstream targets. Genes Chromosomes Cancer 22: 157-163, 1998.

18. Ibrahim N and Haluska FG: Molecular pathogenesis of cutaneous melanocytic neoplasms. Annu Rev Pathol 4: 551-579, 2009.

19. Curtin JA, Fridlyand J, Kageshita T, Patel HN, Busam KJ, Kutzner H, Cho KH, Aiba S, Bröcker EB, LeBoit PE, et al: Distinct sets of genetic alterations in melanoma. N Engl J Med 353: 2135-2147, 2005.

20. Roll DM, Ireland CM, Lu HSM and Clardy J: Fascaplysin, an unusual antimicrobial pigment from the marine sponge Fascaplysinopsis Sp. J Org Chem 53: 3276-3278, 1988.

21. Soni R, Muller L, Furet P, Schoepfer J, Stephan C, Zumstein-Mecker S, Fretz H and Chaudhuri B: Inhibition of cyclin-dependent kinase $4(\mathrm{Cdk} 4)$ by fascaplysin, a marine natural product. Biochem Biophys Res Commun 275: 877-884, 2000.

22. Shafiq MI, Steinbrecher T and Schmid R: Fascaplysin as a specific inhibitor for CDK4: Insights from molecular modelling. PLoS One 7: e42612, 2012.

23. Yan X, Chen H, Lu X, Wang F, Xu W, Jin H and Zhu P: Fascaplysin exert anti-tumor effects through apoptotic and anti-angiogenesis pathways in sarcoma mice model. Eur J Pharm Sci 43: 251-259, 2011.

24. Segraves NL, Robinson SJ, Garcia D, Said SA, Fu X, Schmitz FJ, Pietraszkiewicz H, Valeriote FA and Crews P: Comparison of fascaplysin and related alkaloids: A study of structures, cytotoxicities, and sources. J Nat Prod 67: 783-792, 2004.

25. McArthur AG, Young RJ, Sheppard KE, Mar V, Waldeck K, Fox SB, Kelleher FC, Liu W, Dobrovic A, Pearson R, et al: Clinical significance of genomic alterations of the CDK4pathway and sensitivity to the CDK4 inhibitor PD0332991 in melanoma. J Clin Oncol 30: 8520, 2012.

26. Herlyn M, Balaban G, Bennicelli J, Guerry D IV, Halaban R, Herlyn D, Elder DE, Maul GG, Steplewski Z, Nowell PC, et al: Primary melanoma cells of the vertical growth phase: Similarities to metastatic cells. J Natl Cancer Inst 74: 283-289, 1985. 
27. Lu XL, Zheng YL, Chen HM, Yan XJ, Wang F and Xu WF: Anti-proliferation of human cervical cancer HeLa cell line by fascaplysin through apoptosis induction. Yao Xue Xue Bao 44: 980-986, 2009 (In Chinese).

28. Fry DW, Harvey PJ, Keller PR, Elliott WL, Meade M, Trachet E, Albassam M, Zheng X, Leopold WR, Pryer NK, et al: Specific inhibition of cyclin-dependent kinase 4/6 by PD 0332991 and associated antitumor activity in human tumor xenografts. Mol Cancer Ther 3: 1427-1438, 2004.

29. Finn RS, Dering J, Conklin D, Kalous O, Cohen DJ, Desai AJ, Ginther C, Atefi M, Chen I, Fowst C, et al: PD 0332991, a selective cyclin D kinase $4 / 6$ inhibitor, preferentially inhibits proliferation of luminal estrogen receptor-positive human breast cancer cell lines in vitro. Breast Cancer Res 11: R77, 2009.

30. Sanchez-Martinez C, Gelbert L, Shannon H, De Dios A, Staton BA, Ajamie RT, Sawada G, Wishart GN and Raub TJ: LY2835219, a potent oral inhibitor of the cyclin-dependent kinases 4 and $6(\mathrm{CDK} 4 / 6)$ that crosses the blood-brain barrier and demonstrates in vivo activity against intracranial human brain tumor xenografts. Mol Cancer Ther 10: B234, 2011
31. Walsh N, Kennedy S, Larkin AM, Tryfonopoulos D, Eustace AJ, Mahgoub T, Conway C, Oglesby I, Collins D, Ballot J, et al: Membrane transport proteins in human melanoma: Associations with tumour aggressiveness and metastasis. $\mathrm{Br} \mathrm{J}$ Cancer 102: $1157-1162,2010$

32. Young RJ, Waldeck K, Martin C, Foo JH, Cameron DP, Kirby L, Do H, Mitchell C, Cullinane C, Liu W, et al: Loss of CDKN2A expression is a frequent event in primary invasive melanoma and correlates with sensitivity to the CDK4/6 inhibitor PD0332991 in melanoma cell lines. Pigment Cell Melanoma Res 27: 590-600, 2014.

33. Hörmann A, Chaudhuri B and Fretz H: DNA binding properties of the marine sponge pigment fascaplysin. Bioorg Med Chem 9: 917-921, 2001.

34. Jalili A, Wagner C, Pashenkov M, Pathria G, Mertz KD, Widlund HR, Lupien M, Brunet JP, Golub TR, Stingl G, et al: Dual suppression of the cyclin-dependent kinase inhibitors CDKN2C and CDKN1A in human melanoma. J Natl Cancer Inst 104: 1673-1679, 2012. 